\title{
A Comparative Study of Open Septorhinoplasty with Spreader Graft and Auto-Spreader Flap in Patients with Nasal Obstruction
}

\author{
Naguib MB, Rifaat M, Madian YT, Elnahriry T and Eldeeb W* \\ Department of Otolaryngology, Head and Neck surgery, Suez Canal University, Egypt \\ *Corresponding Author: Eldeeb W, Department of Otolaryngology, Head and Neck \\ surgery, Suez Canal University, Egypt.
}

\author{
Received: April 19, 2020 \\ Published: May 30, 2020 \\ (c) All rights are reserved by Eldeeb W., \\ et al.
}

\begin{abstract}
Background: The 'anterior spreader flap' or auto-spreader flap is a new minimally invasive technique, for the treatment of nasal valve insufficiency or stenosis and can be used as an alternative technique for spreader grafts. This study was done to compare between the spreader graft and auto-spreader flap in open approach reduction rhinoplasty regarding postoperative clinical airway, operative time as well as the aesthetic outcomes.

Methods: 32 Patients were randomly allocated into group (A): Open reduction rhinoplasty for hump removal with spreader grafts and group (B): Open reduction rhinoplasty for hump removal with auto-spreader flaps.

Results: Thirty two patients were 14 males (43.75\%) and 18 females (56.25\%). Regarding the operative time, the auto-spreader flap was shorter in operative time in comparison to the spreader graft. The mean duration of operation in auto-spreader flap was 49.2 minutes \pm 10.8 , while it was 91.1 minutes \pm 12.1 in spreader graft. The difference between the two procedures was highly statistically significant $(\mathrm{P}=0.001)$. According to the line of treatment, there was a great improvement in the patients' symptom of nasal obstruction according to NOSE scale either treated by spreader graft or auto spreader flap. Despite of this improvement of nasal obstruction, it was statistically insignificant either after three or six months postoperative $(P>0.05)$. Irrespective of the surgical procedures done in this study; either spreader grafts or auto-spreader flaps, the overall aesthetic satisfaction was about $60 \%$ (19 of 32). Only $18 \%$ ( 6 of 32) experienced unsatisfactory results and $22 \%$ (7 of 32) with mild or partial satisfaction. Regarding aesthetic outcome according to the line of treatment, it was found that $81.3 \%$ of patients treated by spreader graft (group A) were satisfied, and $12.5 \%$ reported mild improvement. Only one case (6.3\%) was reported with unsatisfactory aesthetic outcomes. In group (B), treated by auto spreader flap, 37.5\% of patients were satisfied, $31.3 \%$ mild improvement and 31.3\% experienced unsatisfactory results. The difference between two groups was statistically significant $(\mathrm{P}=0.038)$.

Conclusion: This difference between both groups concluded that spreader graft has better aesthetic outcomes in comparison with auto spreader flap. However, both are very effective line of treatment regarding the nasal obstruction at the area of nasal valve. Keywords: Septorhinoplasty; Spreader Graft; Auto-Spreader Flap; Nasal Obstruction
\end{abstract}

\section{Introduction}

Spreader grafts are widely considered to be the mainstay of treatment for insufficient internal nasal valve and are commonly placed preventively during rhinoplasty, after hump removal, to avoid middle vault collapse [1]. In addition, the superior widening effect of spreader grafts over the nasal valve has favorable results in olfactory function in primary septorhinoplasty patients.

The 'anterior spreader flap' or auto-spreader flap is a new minimally invasive technique, for the treatment of nasal valve insufficiency or stenosis [7] and can be used as an alternative technique for spreader grafts [8-10]. It was introduced by Fomon [11] and further developed by Gruber [13]. This auto-spreader flap is a technique in which the upper lateral cartilage is rolled on itself to form a spreader flap. This technique avoids harvesting and carving cartilage for grafting from other locations. This technique is limited in cases of deviated dorsal septum and asymmetric dorsal aesthetic lines $[8,12]$.

Despite the spreader grafts are widely used in reduction rhinoplasty after nasal hump removal to manage the flat or open roof, but no randomized controlled clinical trials to compare their effects on nasal valve with the new technique anterior spreader flap which this study will try to address.

\section{Aim of the Study}

The aim of this study is to compare between the spreader graft and auto-spreader flap in open approach reduction rhinoplasty regarding postoperative clinical airway improvement as assessed by NOSE scale. 


\section{Subjects and Methods}

This prospective randomized controlled clinical trial (RCCT) was conducted in Suez Canal University Hospital after getting the approval from the research and ethics committee of the university, in the period from March $1^{\text {st }} 2017$ to $31^{\text {st }}$ March 2019.

Patients attending to OPD ENT clinic of Suez Canal University Hospital with the complain of nasal obstruction were examined and evaluated according to the following inclusion and exclusion criteria:

\section{Inclusion criteria}

Patients who are unsatisfied of the shape of their nose due to nasal hump in addition to nasal obstruction, unsatisfied patients with previous nasal surgery complicated by nasal obstruction due to nasal valve stenosis, middle vault collapse.

\section{Exclusion criteria}

Deviated dorsal septum, asymmetric dorsal aesthetic lines (both are limitations for the auto-spreader flap), Patients for cosmetic complain only without nasal obstruction, hypertrophied inferior turbinates, chronic rhinosinusitis and nasal polyposis.

After examination and evaluation of patients with nasal obstruction, the selected patients according to the inclusion and exclusion criteria were randomized into two groups. Group (A): Open reduction rhinoplasty for hump removal with spreader grafts. Group (B): Open reduction rhinoplasty for hump removal with auto-spreader flaps.

\section{Randomization: Patients were randomly allocated for one group} on a consecutive basis. Odd numbers will be grouped into group (A) while Even numbers will be grouped into group (B).

Sample size: 16 patients in each group [20].

\section{Surgical technique}

All surgeries were done by one team with general anaesthesia and infiltration with lidocaine $(0.5 \%)$ and epinephrine (1:200 $000)$ which was done at least 10 minutes prior to the incision to allow for adequate vasoconstriction. Generally the lower nose and septum was injected with the vasoconstrictors at this time. Marking of the planned incision in the columella with a fine marker prior to injecting it was done. Inverted V-incision was done in the middle of columella. Then marginal or rim incision for exposure of the lower lateral cartilage. Then the mucosa was incised. Great care was taken to avoid violation of the cartilage itself.

\section{The spreader grafts}

The spreader grafts were harvested from septal cartilage according to the original technique described by Sheen [3]. They are shaped in rectangular bars, approximately $2-3 \mathrm{~cm}$ long, $3-5 \mathrm{~mm}$ wide, and $1.5 \mathrm{~mm}$ thick [1] as shown in figure 1.

In case of inadequate septal cartilage due to previous septal surgery or rhinoplasty, auricular conchal cartilage can also be used

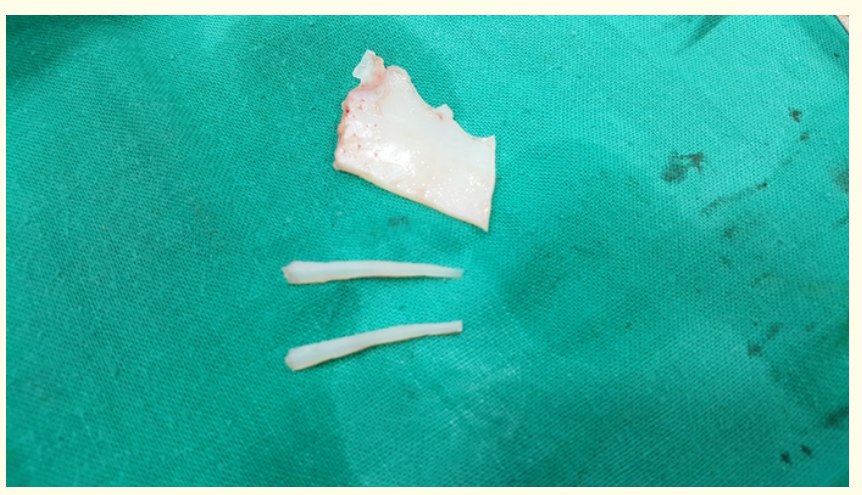

Figure 1: A spreader graft in one subject of this study.

for spreader grafts [19] and in rare cases we can use costal rib cartilage graft (Figure 2).

The next step of the nasal dorsum reconstruction was positioning of the harvested cartilages between the Upper Lateral Cartilages (ULC) and the upper part of septal cartilage on both sides (Figure 3 and 4$)$.

The grafts were fixed to the septal edge at least twice; adjacent to the keystone area cranially and at the anterior septal angle caudally using 5-0 polydioxanone (PDS) sutures (Figure 5).

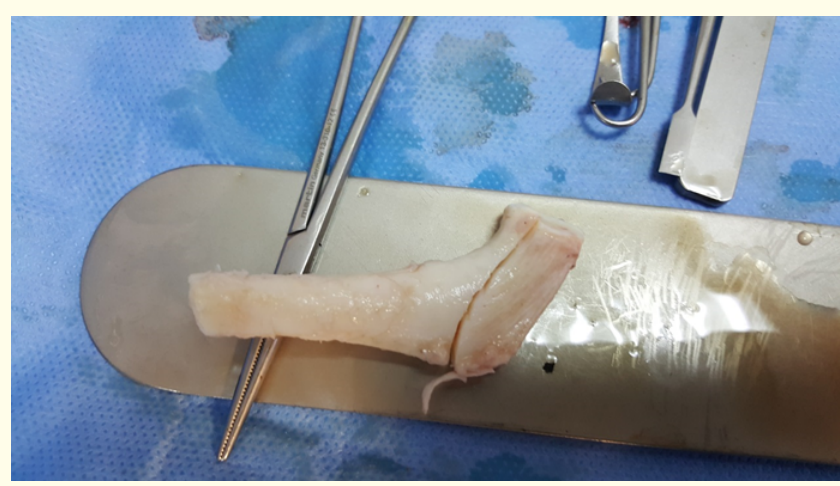

Figure 2: Costal cartilage was used in cases of inadequate septal cartilage.

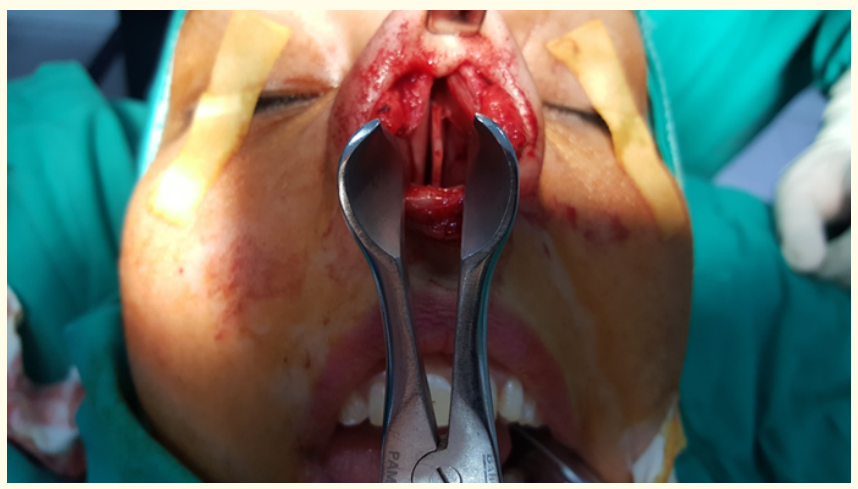

Figure 3: Separation of upper lateral cartilage from the septum. 


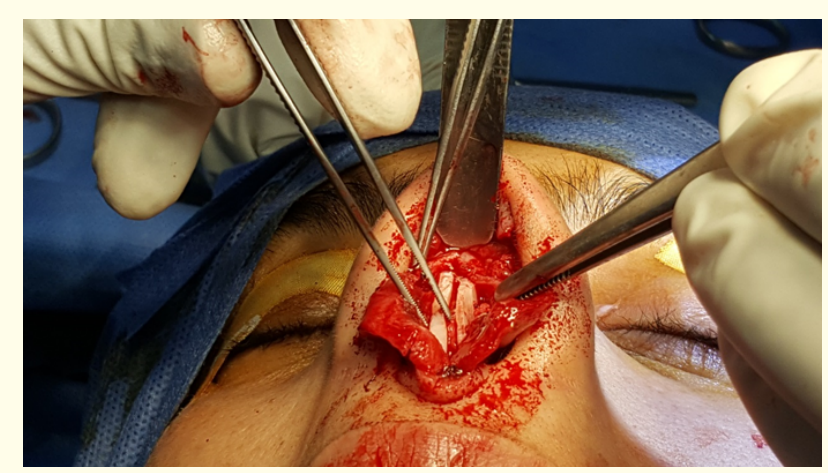

Figure 4: Positioning of a bilateral spreader graft in a patient of this study.

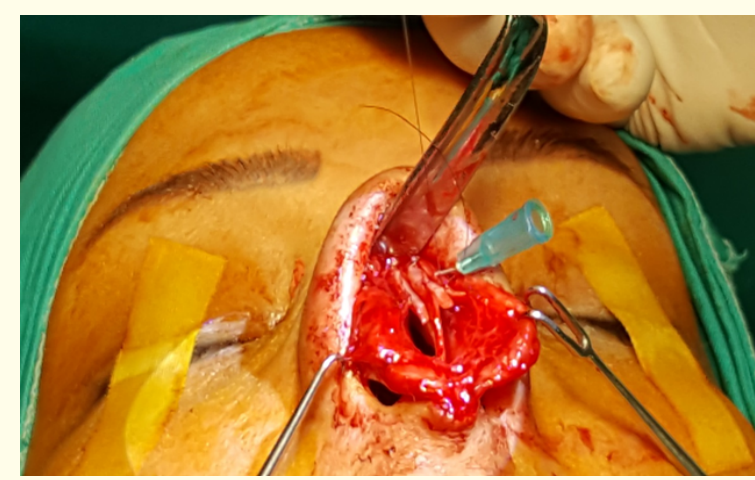

Figure 5: Fixation of a spreader graft by PDS sutures.

\section{The auto-spreader flap}

After incision and cartilage exposure as mentioned for the spreader graft before, the following steps were done with no need for harvesting a graft (Figure 6-8):

- $\quad$ Dissection of the mucosa from ULC.

- Intercartilagenous incision along the caudal edge of the ULC.

- The mucosa was dissected from the medial side of the ULC and from the corresponding septal cartilage.
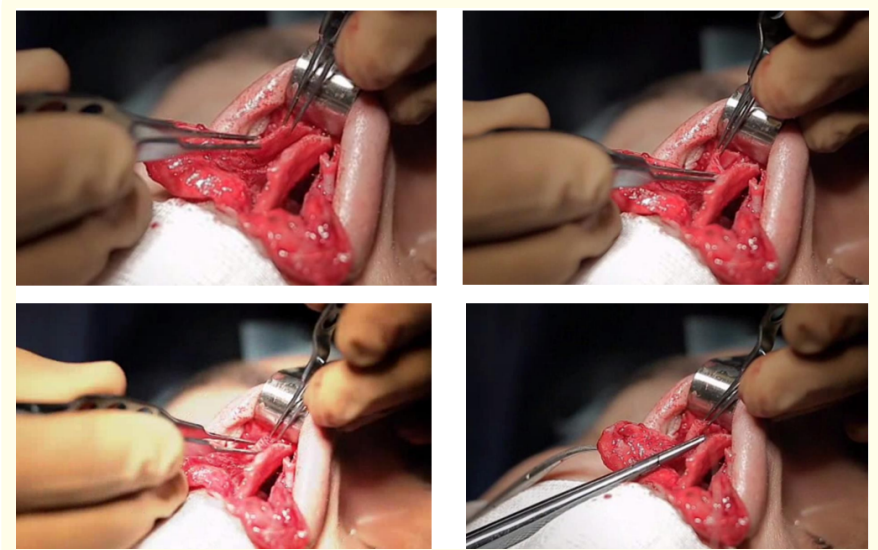

Figure 6: Folding of the ULC inwards toward the septum.
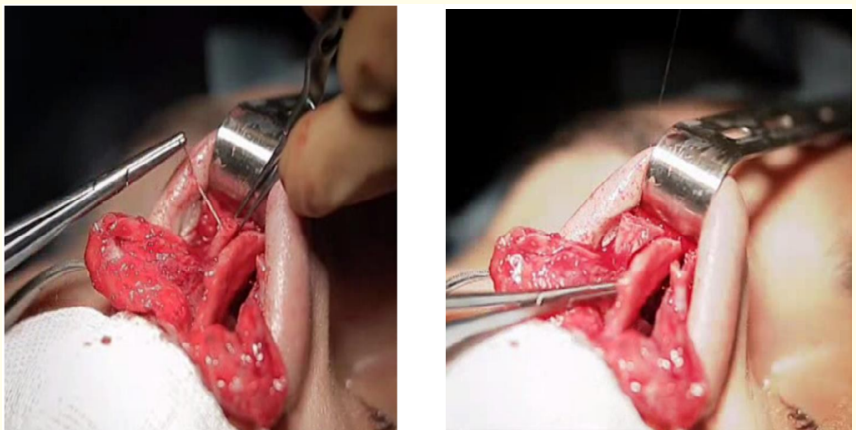

Figure 7: Fixation of the folded ULC with a mattress suture.
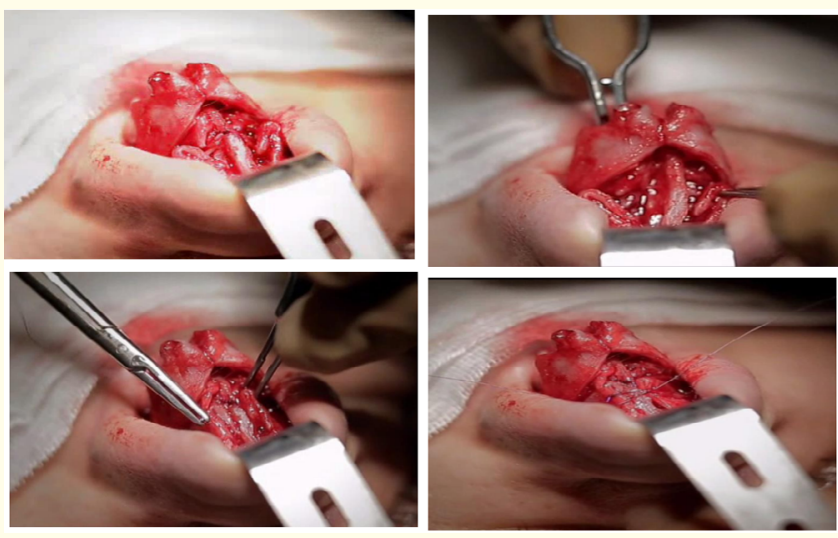

Figure 8: Fixation of the ULC with the septum.

- ULC was folded inwards towards the septum.

- Fixation of the ULC by mattress sutures.

Adhesive tape was applied to the nose. Then external nasal splints were applied to provide more support.

Post-operative evaluation

The patients were observed for any postoperative bleeding and discharged after two days after removal of the nasal packing; if present.

Routine follow up were made monthly for six months postoperative with report of NOSE scale score or any complications. Evaluation of nasal obstruction was repeated at three and six months postoperative as that of preoperative evaluation.

\section{Statistical analysis}

The data were analyzed by the SPSS software.

1. Data were expressed as means, standard deviations (SD), minimum and maximum for the numerical analysis.

2. Correlation between two variables was done using correlation coefficient test.

3. Comparison between two groups was done using student's t-test. 
4. Comparison of multiple groups was done using analysis of variance (ANOVA test) to calculate significant difference.

5. The level of statistical significance was: $\mathrm{P}<0.05$.

\section{Results}

This study was done on thirty two patients complaining of persistent nasal obstruction not responding to medical treatment for long duration. They were 14 males (43.75\%) and 18 females $(56.25 \%)$. The mean age was $34.4 \pm 9.5$ years ranging from 18 to 48 years. The mean age for males was $35.1 \pm 6.1$ ranging from 26 to 45 years, while the mean age for females was $33.9 \pm 11.6$ years ranging from 18 to 48 years.

Regarding the operative time, the auto-spreader flap was shorter in operative time in comparison to the spreader graft. The mean duration of operation in auto-spreader flap was 49.2 minutes \pm 10.8 , while it was 91.1 minutes \pm 12.1 in spreader graft. The difference between the two procedures was highly statistically significant $(\mathrm{P}=0.001)$

Assessment of nasal obstruction was evaluated for all patients three and six months postoperatively using NOSE scale. There was a general decrease in NOSE scale either three or six moths post operatively in comparison with preoperative NOSE scale irrespective of spreader graft or auto spreader flap (Table 3).

\begin{tabular}{|c|c|c|c|}
\hline \multirow{2}{*}{} & \multicolumn{3}{|c|}{ Age } \\
\cline { 2 - 4 } & Total & Male & Female \\
\hline Mean \pm SD & $34.4 \pm 9.5$ & $35.1 \pm 6.1$ & $33.9 \pm 11.6$ \\
\hline Minimum & 18 & 26 & 18 \\
\hline Maximum & 48 & 45 & 48 \\
\hline
\end{tabular}

Table 1: Age distribution according to sex in the study subjects.

\begin{tabular}{|c|c|c|c|}
\hline \multirow{2}{*}{ Type of surgery } & \multicolumn{3}{|c|}{ Operative Time (minutes) } \\
\cline { 2 - 4 } & Mean \pm SD & Min & Max \\
\hline Auto-spreader Flap & $49.2 \pm 10.8$ & 35 & 75 \\
\hline Spreader Graft & $91.1 \pm 12.1$ & 73 & 120 \\
\hline
\end{tabular}

Table 2: Duration of operations conducted in this study $(\mathrm{P}=0.001)$.

\begin{tabular}{|l|c|c|c|c|}
\hline & Number & Min & Max & Mean \pm SD \\
\hline Preoperative & 32 & 20 & 100 & $63.4 \pm 20.7$ \\
\hline Three months & 32 & 5 & 70 & $19.5 \pm 16.1$ \\
\hline Six months & 32 & 5 & 90 & $27.3 \pm 19.8$ \\
\hline
\end{tabular}

Table 3: Mean NOSE scale in the study subjects.

The decrease in NOSE scale was statistically significant after three months postoperatively $(\mathrm{P}<0.05$ ) while it was statistically insignificant after six months postoperative; However, it is still clinically significant (Figure 9) $(\mathrm{P}>0.05)$.

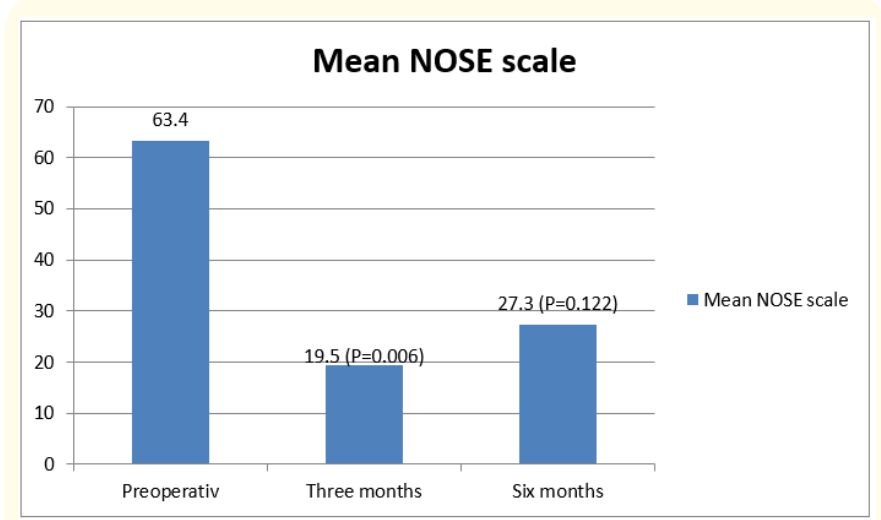

Figure 9: Statistical significance of NOSE scale in the study

According to the line of treatment, there was a great improvement in the patients' symptom of nasal obstruction according to NOSE scale either treated by spreader graft or auto spreader flap as shown in table 4. As shown in figure 10. Despite of this improvement of nasal obstruction, it was statistically insignificant either after three or six months postoperative $(\mathrm{P}>0.05)$.

Irrespective of the surgical procedures done in this study; either spreader grafts or auto-spreader flaps, the overall aesthetic satisfaction was about $60 \%$ (19 of 32). Only $18 \%$ (6 of 32) experienced unsatisfactory results and $22 \%$ ( 7 of 32 ) with mild or partial satisfaction as shown in table 5 .

\begin{tabular}{|l|c|c|c|c|}
\hline & Preoperative & Three months & Six months & N \\
\hline $\begin{array}{l}\text { Spreader } \\
\text { Graft }\end{array}$ & $64.1 \pm 23.5$ & $20.6 \pm 17.7$ & $27.5 \pm 23.5$ & 16 \\
\hline $\begin{array}{l}\text { Auto spread- } \\
\text { er flap }\end{array}$ & $62.8 \pm 18.3$ & $18.4 \pm 14.9$ & $27.2 \pm 16.2$ & 16 \\
\hline Total & $63.4 \pm 20.7$ & $19.5 \pm 16.1$ & $27.3 \pm 19.8$ & 32 \\
\hline
\end{tabular}

Table 4: Mean NOSE scale in the study subjects according to the line of treatment.

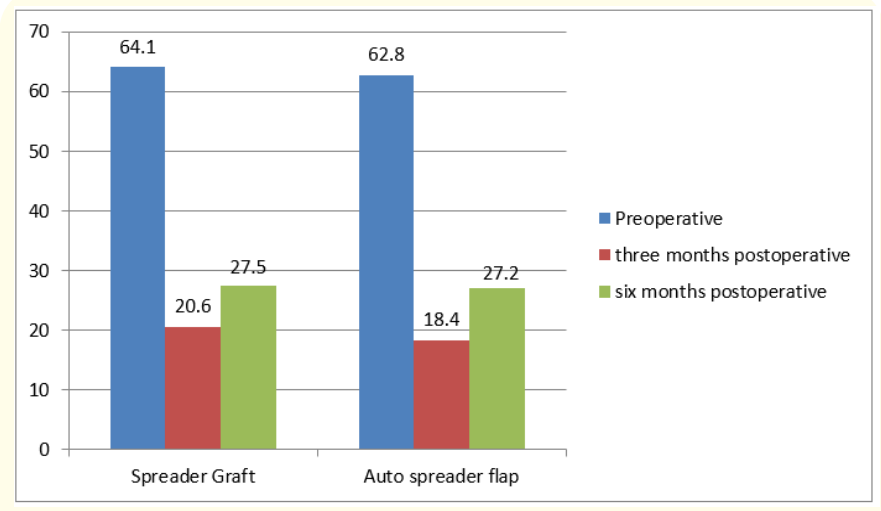

Figure 10: Statistical significance of NOSE scale in the study 


\begin{tabular}{|l|c|c|c|c|}
\hline \multirow{2}{*}{ Type of surgery } & \multicolumn{3}{|c|}{ Aesthetic Satisfaction } & \multirow{2}{*}{ N } \\
\cline { 2 - 4 } & Satisfactory & Mild & Unsatisfactory & \\
\hline Spreader Graft & 13 & 2 & 1 & 16 \\
\hline $\begin{array}{l}\text { Auto-spreader } \\
\text { Flap }\end{array}$ & 6 & 5 & 5 & 16 \\
\hline Total & 19 & 7 & 6 & 32 \\
\hline
\end{tabular}

Table 5: Aesthetic satisfaction in the study.

Regarding aesthetic outcome according to the line of treatment, it was found that $81.3 \%$ of patients treated by spreader graft (group A) were satisfied, and $12.5 \%$ reported mild improvement. Only one case (6.3\%) was reported with unsatisfactory aesthetic outcomes.

In group (B), treated by auto spreader flap, $37.5 \%$ of patients were satisfied, $31.3 \%$ mild improvement and $31.3 \%$ experienced unsatisfactory results. The difference between two groups was statistically significant (Figure 11) $(\mathrm{P}=0.038)$.

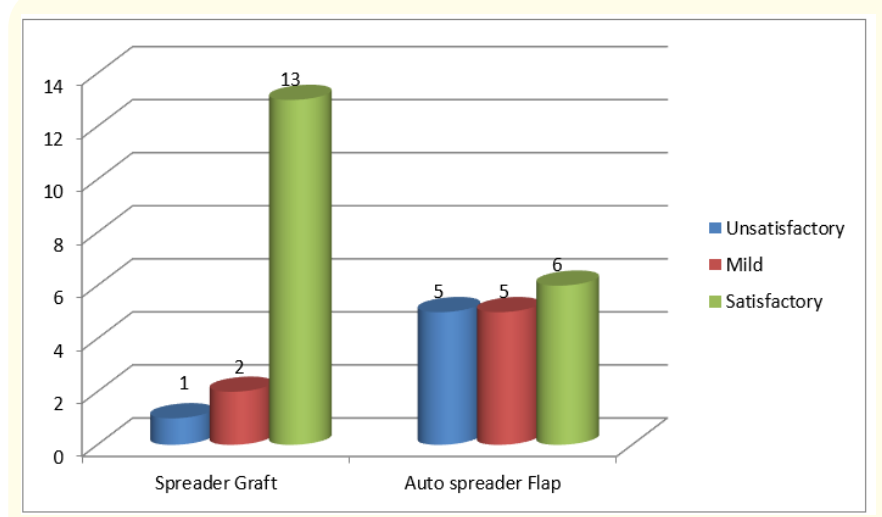

Figure 11: Patients satisfaction for aesthetic outcomes.

This difference between both groups concluded that spreader graft has better aesthetic outcomes in comparison with auto spreader flap. However, both are very effective line of treatment regarding the nasal obstruction at the area of nasal valve.

\section{Discussion}

Chronic nasal airway obstruction is one of the most frequent symptoms with which an otolaryngologist is confronted. Causes of chronic nasal obstruction are multiple and multifactorial, but up to $13 \%$ are caused by nasal valve dysfunction [31-33].

The goal of all described surgical procedures for correction of internal nasal valve dysfunction is widening the internal nasal valve angle and/or preventing it from collapse or narrowing during inspiration $[3,29]$.

Spreader grafts are established standard surgical treatment of internal nasal valve collapse and auto-spreader flaps are recently gained more popularity as an alternative method [36]. This randomized controlled clinical study compares the effectiveness of both surgical procedures.
In this study, the mean operative time for auto-spreader flaps was much less than operative time for spreader grafts (49.2 and 91.1 minutes respectively). Byrd., et al. [9] then Gruber., et al. [30] reported also the same results that were lately supported by Kutubidze [35] regarding more operative time for spreader grafts.

The more operative time for spreader graft is due to the time spent for harvesting a septal cartilage graft, shaping and dissection in the subperichondrial plane for precise pocket to allow insertion of the spreader graft. [3,29]. However, this long operative time has the advantage of direct visualization of the middle third of the nose, so after division of the upper lateral cartilage from the septum, the graft can be precisely positioned and secured in the apex of the nasal valve angle [29]. In addition, Rohrich and Ghavami [4] concluded that the spreader graft is a time wasting procedure with some problem may occur such as dropping of the graft into the mucoperichondrial pocket and graft displacement. Byrd., et al. [9] then Gruber., et al. [30] agreed with these results regarding increased operative time as well as donor site morbidity.

On the other hand, Zojaji., et al. [6] mentioned that auto-spreader flap is a new method that the part of upper lateral cartilage is used as its own graft that contribute to less operative time. Oneal and Berkowitz [10] were among the first to utilize the upper lateral cartilages as spreader grafts, and they coined the term "spreader flap" $[9,10,26]$. Gruber., et al. [30] subsequently referred to this maneuver as an "auto-spreader flap". This technique obviates the need of harvesting cartilage septal graft that contributes to less operative time $[10,18]$. In cases of previous septal surgery with no more adequate septal cartilage, this technique will preclude the need of harvesting ear cartilage, thus saving the patient unnecessary morbidity [12].

In 2004, The Nasal Obstruction Symptom Evaluation (NOSE) scale is validated as a convenient, efficient, simple and diseasespecific quality of life (QOL) instrument designed for assessment of nasal obstruction [14,16,17]. Lam., et al. [15] questioned the utility of quantitative measures as acoustic rhinometry to assess the nasal obstruction objectively as they do not necessarily correlate with the patients symptoms. Then, Lipan and Most [13] have confirmed the effectiveness of the NOSE scale score for postoperative subjective assessment of the nasal airway.

The results of this study are consistent with other studies regarding the improvement of NOSE score postoperatively irrespective of the surgical procedure. The mean decrease of NOSE score in this study for patients treated by spreader grafts was more than 43 and 36 points after three and six months postoperative respectively in comparison with the preoperative mean NOSE score Standlee and Hohman [21] reported almost the same result where their surgical procedures reduced NOSE scores by an average of 46 points. They stated that the mean difference in NOSE scores after septoturbinoplasty and rhinoplasty with spreader graft placement were 40 and 49 respectively across all postoperative time points. 
In their first follow up (mean within 52 days while our study after 90 days), they reported a mean improvement in nose score of 41points for patients who had undergone septoturbinoplasty while patients who have had undergone septorhinoplasty with spreader graft placement reported a mean improvement of 48 points. In our study, first follow up NOSE scores was after 90 days and reported a mean improvement by 43 points. At their second follow up (within 115 to 191 days), they stated improvement in NOSE scores averaged 27 points for the septoturbinoplasty group and 51 points for septorhinoplasty with spreader graft group. This was in contrast to the results of our study that reported improvement for only 36 points on NOSE scores in comparison to 51 points of improvement in Standlee and Hohman [21] study.

Rhee., et al. [27] is consistent with our results. They compared multiple studies [23-26,28] that used NOSE scale to measure nasal surgical outcomes and found that the mean improvement in NOSE score after surgery for nasal obstruction was more than 40 points. Moreover, Standlee and Hohman [21] concluded that rhinoplasty with spreader graft results in great degree of improvement in subjective nasal obstruction and that improvement is more robust, at least on the short term.

Regarding the auto-spreader flap, Bessler., et al. [7] reported significant improvement of NOSE scale up to 53 to 57 points. This is in contrast to our study where the improvement of NOSE scale was 44 and 35 at three and six months postoperative respectively in comparison to the preoperative NOSE score. However, the variation is little and not significant especially both studies showed that there is a great improvement of nasal obstruction postoperative.

Sowder., et al. [36] concluded in his study that spreader flaps are equivalent to the effect of spreader grafts in correction of the nasal obstruction that is due to internal nasal valve (INV) collapse. They used spreader flaps for their patients and they found a mean improvement of 63.4 points, lowering then NOSE scores from a mean of 81.9 to 18.5 . In addition, they reported that there is no difference in spreader grafts group and spreader flaps group regarding the post-operative improvement in NOSE score. Their spreader graft group improved from a mean of 75.4 to 16.9 , for a mean improvement of 58.5 points.

These results are comparable to the results that were done by Chambers., et al. [34] who evaluated INV collapse after septoplasty and complaining of persistent nasal obstruction. All their patients were treated by spreader grafts placement resulting in a great improvement in mean NOSE scores of 53.6 points (75.7 to 22.1) at 6 months postoperative.

Our study is consistent with Sowder., et al. [36] results, where we found that there is improvement of nasal obstruction evaluated by decrease in NOSE scores, either 3 or 6 months postoperative irrespective of using spreader grafts or auto-spreader flaps.
Despite of the same results, we believe that our study is more powerful as it is a randomized controlled clinical trial. So, we avoided any selection bias. In contrast, Sowder., et al. [36] used specific criteria for spreader grafts and spreader flaps. Spreader flaps were placed in patients with short nasal bone, a thin and long nasal dorsum, thin nasal skin, a weak midvault composed of thin ULC and/or thin nasal bones, or preoperative positive modified Cottles maneuver. Spreader grafts were placed in patients with INV stenosis and a preoperative positive modified Cottles test that did not fit the anatomical criteria for spreader flaps. So, the type of graft placed was based on the patients' anatomy as well as the surgeon preferences. Consequently, our study tried to avoid this drawback in Sowder., et al. [36] work by randomization to avoid any selection bias.

Yoo and Most [12] compared the effectiveness of auto spreader techniques for nasal airway preservation in functional group and aesthetic group. They stated that their patients exhibited a slight reduction in their mean NOSE scores denoting improvement, though this was not statistically significant in comparison to the preoperative values. This aesthetic effect was confirmed later by Hussien., et al. [22] who stated that the auto-spreader flap have no effect on the width of the nasal dorsum esthetically to unsatisfactory results. In addition, it has a spring effect that increases the width of internal nasal valve and result in improving the symptoms of nasal obstruction.

On the other hand, their functional group showed that the improvement of mean NOSE scores was statistically significant and were significantly higher than the cosmetic only group. They concluded that auto-spreader flaps are effective in preventing or treating postoperative nasal obstruction even in patients undergoing cosmetic rhinoplasty as well as treatment of midvault over narrowing.

Regarding the aesthetic outcomes in this study, 6 patients out of $32(18 \%)$ experienced unsatisfactory results irrespective of line of treatment. There is one patient (6.3\%) who reported unsatisfactory result in spreader graft group and 5 patients $(31.3 \%)$ in autospreader flap group.

Hassanpour., et al. [5] agreed with our results when they compare the aesthetic and functional outcomes of spreader grafts and auto-spreader flaps. Their subjects experienced dissatisfaction on aesthetic outcomes in $14 \%$ of their patients. Another study analyzed 101 primary cosmetic rhinoplasty, they reported $16 \%$ were unhappy from their aesthetic outcome [23].

These variations between the above mentioned 3 studies may be due to different sample sizes. Another cause that may explain this variation is that the aesthetic outcomes depend on the subjects' desire and the surgeon should be alert whether to agree to such requests of the patients as the outcome may not be satisfiable for patients who have unrealistic expectations [24]. 
In 2014, Saedi., et al. [25] used the auto-spreader flaps in 32 patients for primary rhinoplasty; they found that it was an effective technique in middle vault preservation in nasal plastic surgery.

The most common problem in using an auto-spreader flap is the technique's inability to provide adequate dorsal width compared with spreader grafts. In addition, the use of auto-spreader flap cannot be used in special cases such as crocked nose, minimal dorsal humps and secondary cases [5]. Another drawback of the auto-spreader flap is its inability to address the lower third of the dorsum when not extending down to the anterior septal angle [26]

Our Study concluded that either spreader grafts or autospreader flaps are very effective line of treatment regarding nasal airway obstruction at the area of nasal valve. However, Spreader grafts are superior to the auto-spreader flaps regarding the aesthetic outcomes.

This is also supported by Hassanpour., et al. [5] who concluded that both spreader grafts or auto-spreader flaps techniques can be used in the preservation of the normal internal nasal valve angle as well as restoration of the dorsal aesthetic lines of the nasal dorsum.

\section{Conclusion}

This study showed that both spreader grafts and auto-spreader flaps are very effective in the treatment of INV collapse. However, spreader grafts are more superior to the auto-spreader flaps regarding the aesthetic outcomes. On the other hand; the autospreader flap was shorter operative time in comparison to the spreader graft. The difference was highly statistically significant. NOSE scale score is an effective and useful tool for subjective assessment of nasal airway irrespective of the surgical line of treatment.

\section{Recommendations:}

- Auto-spreader flap should gain more popularity as it is more time saving procedure in comparison to the spreader graft. This will eventually lead to decrease the cost of surgery. However, it is still has its limitations.

- Spreader graft should be of particular interest when we are dealing with aesthetic issue only.

- Nasal packing usually are not required in auto-spreader flap and no risk of postoperative septal hematoma formation.

- Further studies are required to determine the long effects of spreader grafts or auto-spreader flaps and their implication on the nasal airway and internal nasal valve.

\section{Funding}

- There no financial interest or commercial association with any subject matter or products were used in this study.

\section{Ethical Considerations}

The following ethics were considered in this study:

- Both types of surgical intervention in both groups are well established and known. The patients in this study were not be prevented from a more superior and efficient surgical interventions.

- Patients were aware that they participated in such a comparative study.

- Randomization were applied strictly as mentioned in subjects and methods to avoid any bias.

- All surgical interventions were conducted by one surgeon to avoid bias.

- Consent form of approval for surgical procedure were taken from the patients prior to surgery.

- Written consent were also be taken prior taking photos of the patients either pre-operative or post-operative. These photos will never be used for any other purposes unless the patient is completely aware and approved it.

- The medical information of the patients is strictly confidential and is not revealed to unauthorized person. Patients confidentiality form were given to the patient to determine at least two persons only that can get a copy or attain information about his medical condition. Also, the patient has the right not to choose any person to get these information.

\section{Bibliography}

1. Daniel Y. "Functional and aesthetic effects of spreader grafts technique in rhinoplasty". Scripta Scientifica Medica 46.1 (2014): 68-73.

2. Samaha M and RassouliA. "Spreader graft placement in endonasal rhinoplasty: Technique and a review of 100 cases". Plastic Surgery 23.4 (2015): 252-254.

3. Sheen JH. "Spreader graft: a method of reconstructing the roof of the middle nasal vault following rhinoplasty". Plastic and Reconstructive Surgery 73.2 (1984): 230-239.

4. Rohrich RJ and Ghavami A. "Rhinoplasty for middle eastern noses”. Plastic and Reconstructive Surgery 123 (2009): 13431354.

5. Hassanpour SE., et al. "Comparison of Aesthetic and Functional Outcomes of Spreader Graft and Autospreader Flap in Rhinoplasty". World Journal of Plastic Surgery 5.2 (2016): 133-138.

6. Zojaji R., et al. "Quality of life in patients who underwent rhinoplasty”. Facial Plastic Surgery 30 (2014): 593-596.

- There is no external funding for this study. 
7. Bessler S., et al. “Anterior spreader flap technique: a new minimally invasive method for stabilizing and widening the nasal valve". Journal of Plastic, Reconstructive and Aesthetic Surgery 68.12 (2015): 1687-1693.

8. Gruber RP., et al. "The spreader flap in primary rhinoplasty". Plastic and Reconstructive Surgery 119.6 (2007): 1903-1910.

9. Byrd HS., et al. "Using the autospreader flap in primary rhinoplasty”. Plastic and Reconstructive Surgery 119 (2007): 18971902.

10. Oneal RM and Berkowitz RL. "Upper lateral cartilage spreader flaps in rhinoplasty". Aesthetic Surgery Journal 18 (1998): 370-371.

11. FomonS and Caron A. "Collapsedala". Acta Oto-Laryngologica, 51 (1950): 465-484.

12. Yoo S and Most SP. "Nasal airway preservation using the autospreader technique. Analysis of outcomes using a diseasespecific quality of life instruments". Archives of Facial Plastic Surgery 13.4 (2011): 231-233.

13. Lipan MJ and Most SP. "Development of a severity classification system for subjective nasal obstruction". JAMA Facial Plastic Surgery 15.5 (2013): 358-361.

14. Stewart MG., et al. "Development and validation of the Nasal Obstruction Symptom Evaluation (NOSE) scale”. Otolaryngology-Head and Neck Surgery 130.2 (2004): 157-163.

15. Lam DJ., et al. "Comparison of anatomic, physiological, and subjective measures of the nasal airway". The American Journal of Rhinology 20.5 (2006): 463-470.

16. Stewart MG., et al. "Outcomes after nasal septoplasty: results from the Nasal Obstruction Septoplasty Effectiveness (NOSE) study". Otolaryngology-Head and Neck Surgery 130.3 (2004): 283-290.

17. Most SP. "Analysis of outcomes after functional rhinoplasty using a disease-specific quality-of-life instrument". Archives of Facial Plastic Surgery 8.5 (2006): 306-309.

18. Lerma J. "The "lapel" technique". Plastic and Reconstructive Surgery 102.6 (1998): 2274-2275.

19. Murrell GL. "Auricular cartilage grafts and nasal surgery". Laryngoscope 114.12 (2004): 2092-2102.

20. Jaykaran C and Tamoghna B. "How to Calculate Sample Size for Different Study Designs in Medical Research?”. Indian Journal of Psychological Medicine 35.2 (2013): 121-126.

21. Standlee AG and Hohman MH. "Evaluating the Effect of Spreader Grafting on Nasal Obstruction Using the NOSE Scale". Annals of Otology, Rhinology, and Laryngology 126.3 (2017): 219-223.
22. Hussein WK., et al. "Modified autospreader flap for nasal valve support: utilizing the spring effect of the upper lateral cartilage". European Archives of Oto-Rhino-Laryngology 272.2 (2015): 497-504.

23. Salyer KE. "Primary correction of the unilateral cleft lip nose: a 15-year experience". Plastic and Reconstructive Surgery 77 (1986): 558-566.

24. Varedi P., et al. "Spreader graft placement: A simplified technique for young surgeons". International Journal of Oral and Maxillofacial Surgery 43 (2014): 1216-1217.

25. Saedi B., et al. "Spreader flaps do not change early functional outcomes in reduction rhinoplasty: a randomized control trial". American Journal of Rhinology and Allergy 28 (2014): 7074.

26. Manavbaşı YI and Başaran I. "The role of upper lateral cartilage in dorsal reconstruction after hump excision: section 1. Spreader flap modification with asymmetric mattress suture and extension of the spreading effect by cartilage graft". Aesthetic Plastic Surgery 35 (2011): 487-493.

27. Rhee JS., et al. "A systematic review of patient-reported nasal obstruction scores". JAMA Facial Plastic Surgery 16.3 (2014): 219-225.

28. Most SP. "Anterior septal reconstruction: outcomes after a modified extracorporeal septoplasty technique". Archives of Facial Plastic Surgery 8.3 (2006): 202-207.

29. Andre RF., et al. "Endonasal spreader graft placement as treatment for internal nasal valve insufficiency: no need to divide the upper lateral cartilages from the septum". Archives of Facial Plastic Surgery 6.1 (2004): 36-40.

30. Gruber RP., et al. "Dorsal reduction and spreader flaps". Aesthetic Surgery Journal 31.4 (2011): 456-464.

31. Helal MZ., et al. "Effects of rhinoplasty on the internal nasal valve: a comparison between internal continuous and external perforating osteotomy". Annals of Plastic Surgery 64.5 (2010): 649-657.

32. Schlosser RJ and Park SS. "Functional rhinoplasty. Operative techniques in otolaryngology". Head and Neck Surgery 10.3 (1999): 203-208.

33. Elwany $\mathrm{S}$ and Thabet $\mathrm{H}$. "Obstruction of the nasal valve". The Journal of Laryngology and Otology 110.3 (1996): 221-224.

34. Chambers KJ., et al. "Evaluation of Improvement in Nasal Obstruction Following Nasal Valve Correction in Patients with a History of Failed Septoplasty". JAMA Facial Plastic Surgery 17.5 (2015): 347-350. 
35. Kutubidze A. "Nasal dorsal aesthetic lines and rhinoplasty technical tricks". Plastic and Aesthetic Research 2 (2015): 315319.

36. Sowder JC., et al. "Use of Spreader Flaps without Dorsal Hump Reduction and the Effect on Nasal Function". JAMA Facial Plastic Surgery 19.4 (2017): 287-292.

\section{Assets from publication with us}

- Prompt Acknowledgement after receiving the article

- Thorough Double blinded peer review

- Rapid Publication

- Issue of Publication Certificate

- High visibility of your Published work

Website: https://www.actascientific.com/

Submit Article: https://www.actascientific.com/submission.php Email us: editor@actascientific.com

Contact us: +919182824667 